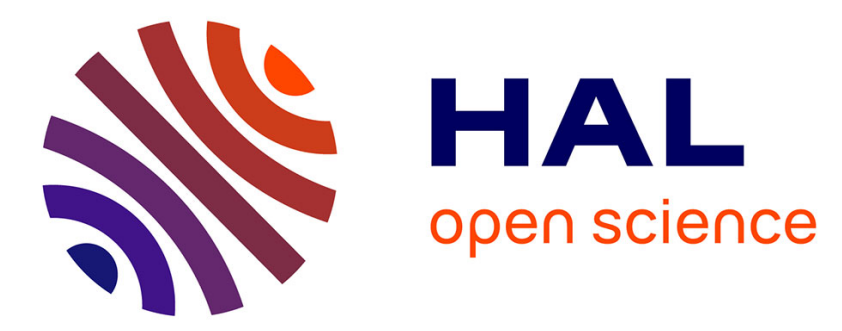

\title{
On the estimation of water pure compound parameters in association theories
}

Andreas Grenner, Georgios M. Kontogeorgis, Michael L. Michelsen, Georgios K. Folas

\section{- To cite this version:}

Andreas Grenner, Georgios M. Kontogeorgis, Michael L. Michelsen, Georgios K. Folas. On the estimation of water pure compound parameters in association theories. Molecular Physics, 2007, 105 (13-14), pp.1797-1801. 10.1080/00268970701416597 . hal-00513102

\author{
HAL Id: hal-00513102 \\ https://hal.science/hal-00513102
}

Submitted on 1 Sep 2010

HAL is a multi-disciplinary open access archive for the deposit and dissemination of scientific research documents, whether they are published or not. The documents may come from teaching and research institutions in France or abroad, or from public or private research centers.
L'archive ouverte pluridisciplinaire HAL, est destinée au dépôt et à la diffusion de documents scientifiques de niveau recherche, publiés ou non, émanant des établissements d'enseignement et de recherche français ou étrangers, des laboratoires publics ou privés. 


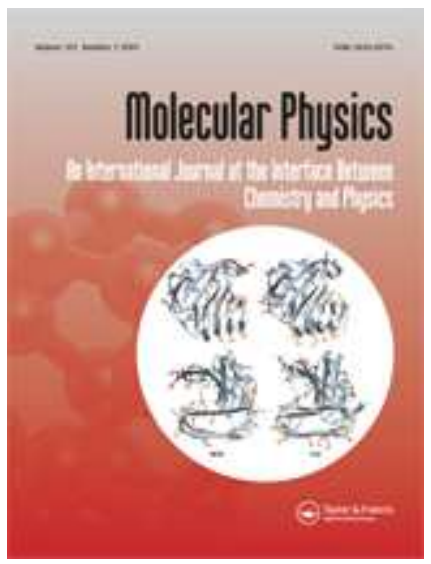

\section{On the estimation of water pure compound parameters in association theories}

\begin{tabular}{|r|l|}
\hline Journal: & Molecular Physics \\
\hline Manuscript ID: & TMPH-2007-0076.R1 \\
\hline Manuscript Type: & Research Note \\
\hline Date Submitted by the & 23-Apr-2007 \\
\hline Complete List of Authors: & $\begin{array}{l}\text { Grenner, Andreas; Technical University of Denmark, Centre for } \\
\text { Phase Equilibria and Separation Processes (IVC-SEP), Department } \\
\text { of Chemical Engineering } \\
\text { Kontogeorgis, Georgios; Technical University of Denmark, Centre } \\
\text { for Phase Equilibria and Separation Processes (IVC-SEP), } \\
\text { Department of Chemical Engineering } \\
\text { Michelsen, Michael; Technical University of Denmark, Centre for } \\
\text { Phase Equilibria and Separation Processes (IVC-SEP) } \\
\text { Folas, Georgios; Technical University of Denmark, Centre for Phase } \\
\text { Equilibria and Separation Processes (IVC-SEP), Department of } \\
\text { Chemical Engineering }\end{array}$ \\
\hline Keywords: & \begin{tabular}{l} 
Association thory, SAFT, Water, Parameter Estimation \\
\hline
\end{tabular} \\
\hline
\end{tabular}

\section{(5) ScholaroNE \\ Manuscript Central}


1

2

3

4

5

6

7

8

9

\title{
RESEARCH NOTE
}

\section{On the estimation of water pure compound parameters in} association theories

Andreas Grenner, Georgios M. Kontogeorgis*, Michael L. Michelsen, and Georgios K. Folas

Centre for Phase Equilibria and Separation Processes (IVC-SEP), Department of Chemical Engineering, Technical University of Denmark, DK-2800 Lyngby,

Denmark

*Corresponding author. Telephone: +45 452528 59. Fax: +45 458822 58. E-mail: gk@kt.dtu.dk

\begin{abstract}
Determination of the appropriate number of association sites and estimation of parameters for association (SAFT-type) theories is not a trivial matter. Building further on a recently published manuscript by Clark et al. [1], this work investigates aspects in parameter estimation for water using two different association theories. Their performance for various properties as well as against the results presented by Clark et al. [1] is demonstrated.
\end{abstract}




\section{Association schemes for water and degeneracy of parameters}

As mentioned in this abstract, Clark et al. [1] have published recently a manuscript about the choice of association sites for water for use in SAFT-type models. The article emphasizes the care that must be exercised when choosing parameters for water and other associating fluids with SAFT-type theories (or other multiparameter models) as there is a clear degeneracy in the model parameters when these are regressed from pure compound vapour pressures and liquid densities.

It is of interest to investigate whether the same conclusions hold for other SAFTtype approaches.

Indeed, several sets of water and other associating fluid parameters can be obtained from SAFT-type approaches which can represent vapour pressure and liquid density data in a satisfactory manner. We have previously showed this for water and other fluids [2,3] using the CPA (Cubic-Plus-Association) [4] equation of state (which uses the same association term as SAFT), while in the case of PC-SAFT [5] this is demonstrated in figure 1.

It is useful, as Clark et al. [1] have shown in their figure 2, to investigate the search for optimal parameters by plotting contours of the absolute average deviation with fixed dispersions and hydrogen bonding energy while fitting the remaining pure compound parameters. The water parameters published by Grenner et al. [6] (dispersion energy $\varepsilon=180.3 \mathrm{~K}$ and association energy- $\varepsilon^{\mathrm{HB}}=1804.22 \mathrm{~K}$ ) are theoretically based values. Errington et al.[7] obtained, based on molecular simulations studied, values between $\varepsilon=74-160 \mathrm{~K}$ for the dispersion energy of water. $\underline{\text { Koh et al. }[8] \text { report for the association energy a value of } 1813 \mathrm{~K} \text {. These parameters }}$ belong to a minimal surface area as shown in figure 1a (dark blue). We did not use Deleted: use Deleted: Deleted: for

Deleted: the

Deleted: dispersion energy $\varepsilon=180.3 \mathrm{~K}$ and association energy- $\varepsilon^{\mathrm{HB}}=1804.22 \mathrm{~K}$ which parameters with the lowest deviations of figure 1a because we used a third 
Input from other properties should be used for selecting the optimum set of pure compound parameters. In our view, these should primarily be readily measurable and widely available properties like enthalpies of vaporization and second Virial coefficients. Input from spectroscopy like monomer fractions, as used by Clark et al. [1], is of course valuable although to our knowledge and for pure compounds such data is available only for water and a few alcohols. The choice of the optimum parameter set is discussed in the next section.

\section{Selection of appropriate water parameters}

Clark et al. [1] have discussed how appropriate parameters can be selected for association theories like the SAFT-VR [13], in their work. An interesting property, not directly used in the parameter estimation, is the enthalpy of vaporization. 
According to Clark et al. [1] and as showed in their figure 5, the performance of SAFT-VR is essentially the same for the enthalpy of vaporization of water no matter the parameter set (and association scheme) used. The calculated values with SAFT-VR are not in good agreement with the experimental data and the authors [1] conclude that "nothing in or comparisons with ... enthalpy of vaporization can be used to select one set of optimal parameters for water".

As figure 2 shows, other association models like PC-SAFT and CPA perform substantially better than SAFT-VR for this property. As the performance of all three models for vapour pressures is essentially equivalent, the improved enthalpies of vaporization must be primarily attributed to the better vapour volumes or compressibilities achieved.

Clark et al. [1] find great sensitivity in the performance of SAFT-VR with various parameter sets for water against the monomer data obtained from spectroscopy and reported by Luck [15] more than 25 years ago. We find a similar sensitivity as shown in figures 3 and 4 , although our results are not quite as good as those reported by Clark et al. [1] using the optimum set in their work (W1 in their figure 7).

We have no intention to underestimate the importance of spectroscopic data, as we have ourselves used them for testing the models [11]. Especially such monomer data for mixtures (associating/inert compounds like alcohol-hydrocarbons) are very useful as several mixture data have indeed been reported and new measurements continue to appear in the literature e.g. $[16,17]$. However, spectroscopic monomeric 


\section{The use of mixture data in parameter selection}

Mixture data are useful but should only be used for parameter evaluation of associating compounds. Clark et al. [1] have used water-methanol VLE data for this purpose but cross-associating systems cannot be considered to be a real test of the parameters of any of the compounds involved. The effect of cross-association with the requirement of combining rules used will obscure judgement. Moreover, watermethanol is not a very non-ideal system. A more useful test is to use more sensitive data for the associating compound in question with an inert compound e.g. n-alkane 
i.e. in this case to use water-alkane LLE data. When this is done, indeed different sets yield different results and choice of optimum sets and association schemes can be achieved e.g. as shown in figure 5 for PC-SAFT and CPA.

The use of mixture data especially for associating/inert mixtures is possibly the ultimate test for selecting optimum parameters, as parameters which are obtained by optimizing various pure compound properties may not always be the optimum ones for mixture calculations. This is evident from figure 6 and table 1, where the published PC-SAFT 4C-water parameters [6] perform better than the ones estimated here based on all three properties (vapour pressures, liquid densities and enthalpies of vaporization).

Concluding remarks

Optimal parameter estimation procedures for water are still missing in relation to molecular theories. Even for rather similar equations of state like SAFT-VR and PC-SAFT different results were obtained. Especially interesting is the fact that these models use essentially the same theory to model hydrogen bonds but still rather different values for the association energy (SAFT-VR [1] e.g. parameter set W1: $\varepsilon_{\mathrm{HB}}^{\mathrm{HB}} / \mathrm{k}=1400.00 \mathrm{~K}$ and PC-SAFT [6]: $\varepsilon_{\mathrm{HB}}^{\mathrm{HB}} / \mathrm{k}=1804.22 \mathrm{~K}$ ). These differences may be due to various reasons, e.g. different experimental data used in the parameter estimation (especially the temperature range of the data is of great importance), different constraints for the parameters or different number of parameters (SAFTVR: 6 adjustable parameters, PC-SAFT: 5 adjustable parameters). Additionally, it seems that contributions e.g. of hydrogen bonding or dipole-dipole interactions are 
incorporated in the parameters of different SAFT type models in different ways, e.g. via the two energetic parameters $\varepsilon$ (dispersion energy) and $\varepsilon_{-}^{\mathrm{HB}}$ (association energy). $\underline{\text { All } \varepsilon \text { values of the } 4 \text { different parameter sets of Clark et al. [1] are higher compared }}$ to the value of Grenner et al. [6], and the $\varepsilon^{\mathrm{HB}}$ values of Clark et al. are accordingly all lower than those of Grenner et al. However, Grenner et al. use theoretically confirmed values to constrain their parameters and the applicability for several mixtures with alkanes, amines or glycols $[6,23]$ confirm the validity of this procedure.

\section{References}

[1] G. N. I._Clark, A. J. Haslam, A. Galindo, G. Jackson, Molec. Phys. 104, 3562 (2006).

[2] I V. Yakoumis, G. M. Kontogeorgis, E. C. Voutsas, E. M. Hendriks, D. P. Tassios, Ind. Eng. Chem. Res. 37, 4175 (1998).

[3] S. O. Derawi, M. L. Michelsen, G. M. Kontogeorgis, E. H. Stenby, Fluid Phase Equilib. 209, 163 (2003).

[4] G. M. Kontogeorgis, E. C. Voutsas, I V. Yakoumis, D. P. Tassios, Ind. Eng. Chem. Res. 35, 4310 (1995).

[5] J. Gross; G. Sadowski, Ind. Eng. Chem. Res. 40, 1244 (2001).

[6] A. Grenner, J. Schmelzer, N. von Solms, G. M. Kontogeorgis, Ind. Eng. Chem. Res. 45, 8170 (2006).

[7] J. R Errington, G. C. Boulougouris, I. G. Economou, A. Z. Panagiotopoulos, D. N. Theodorou, J. Phys. Chem. B 102, 8865 (1998). 
[8] C. A. Koh, H. Tanaka, J. M. Walsh, K. E. Gubbins, J. A. Zollweg, Fluid Phase Equilib. 83, 51 (1993).

[9] www.nist.gov

Deleted: 7

Deleted: 8

[10] G. M. Kontogeorgis, M. L. Michelsen, G. K. Folas, S. Derawi, N. von Solms, E. H. Stenby, Ind. Eng. Chem. Res. 45, 4855 (2006).

[11] N. von Solms, M. L. Michelson, C. P. Passos, S. O. Derawi, S.O.; G. M. Kontogeorgis, Ind. Eng. Chem. Res. 45, 5368 (2006).

[12] S. H. Huang, M. Radosz, Ind. Eng. Chem. Res. 29, 2284 (1990).

[13] A. Gil-Villegas, A. Galindo, P. J. Whitehead, S. J. Mills, G. Jackson, and A. N. Burgess, J. Chem. Phys. 106, 4168 (1997).

[14] G. M. Kontogeorgis, I. V. Yakoumis, H. Meijer, E. Hendriks, T. Moorwood, Fluid Phase Equilib. 158-160, 201 (1999).

[15] W. A. P. Luck, Angew. Chem., Intl. Ed. Engl. 19, 28 (1980).

[16] R. B. Gupta, R. L. Brinkley, Ind. Eng. Chem. Res. 37, 4823 (1998).

[17] R. B. Gupta, R. L. Brinkley, AIChE J. 44, 207, (1998).

[18] I. Nezbeda, U. Weingerl; Molec. Phys. 99, 1595 (2001).

[19] J. Solvák, I. Nezbeda; Molec. Phys. 101, 798 (2003).

[20] J. Gross; G. Sadowski, Ind. Eng. Chem. Res. 41, 5510 (2002).

[21] C. Tsonopoulos, Fluid Phase Equilib. 21, 156 (1999).

[22] M, Broul, K. Hlavaty, J. Linek, Collect. Czech. Chem. Commun. 34, 3428 (1969).

[23] A.Grenner, G. M. Kontogeorgis, N. von Solms, M. L. Michelsen, Fluid Phase Equilib. Accepted for publicaiton.
Deleted: 9

Deleted: 0

Deleted: 1

Deleted: 2

Deleted: 3

Deleted: 4

Deleted: 5

Deleted: 16

Deleted: 17

Deleted: 18

Deleted: II 
1

2

3

4

5

6

7

8

Table 1. PC-SAFT results for water-methanol VLE at $333.15 \mathrm{~K}$. Water pure compound parameter of this work as presented in the caption of figure 4 and Grenner et al. 2006 parameters from [6]. The methanol pure compound parameter by Gross and Sadowski 2002 [20] parameters are used. The experimental data are taken from Broul et al. [22]. 

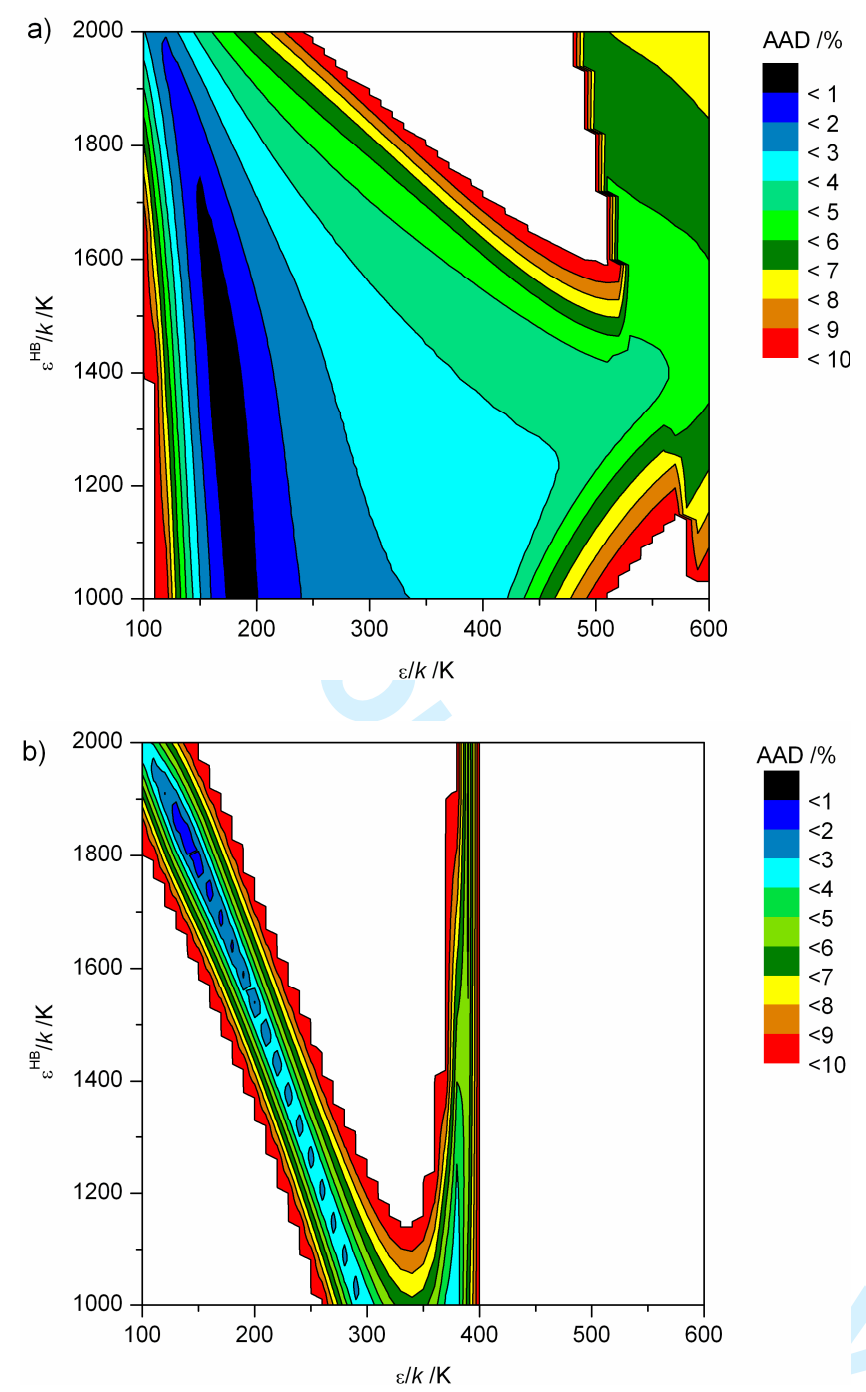

Figure 1. Contour plot for the percentage absolute average deviation (AAD $/ \%$ ) of the vapour pressure and liquid density predicted by PC-SAFT of water with the $4 \mathrm{C}$ scheme. a) The dispersion energy $\varepsilon / \mathrm{k}$ and the hydrogen bonding energy $\varepsilon^{\mathrm{HB}} / \mathrm{k}$ were fixed at each point. The three other pure compound parameters segment diameter- $\sigma$, segment number-m and association volume- $\mathrm{K}^{\mathrm{HB}}$ were optimized on vapour pressure and liquid density data from NIST [9] in a reduced temperature range of 0.5-0.9. b) Similar to plot a) but the segment number-m was fixed to $m=1.5$. The parameters published by Grenner et al. [6] use theoretically justified values $\mathrm{m}=1.5, \varepsilon=180.3 \mathrm{~K}$ and $\varepsilon^{\mathrm{HB}}=1804.22 \mathrm{~K}$. 


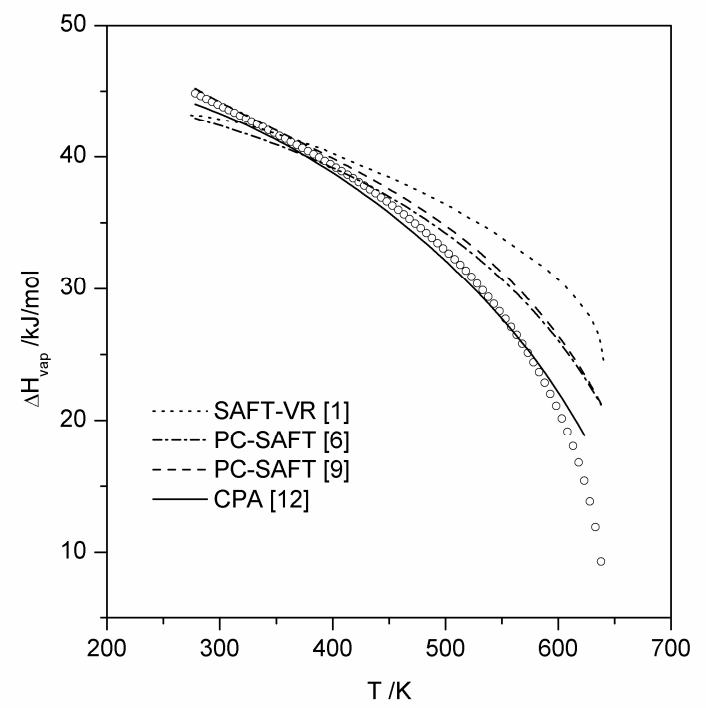

Figure 2. Enthalpy of vaporization of water with CPA parameter taken from Kontogeorgis et al. [14], PC-SAFT using parameters from [6] and [11]. SAFT-VR Deleted: 2 Deleted: 9 results are from [1]. All parameters use a 4C scheme. Experimental data are taken Deleted: 7 from NIST [9] 


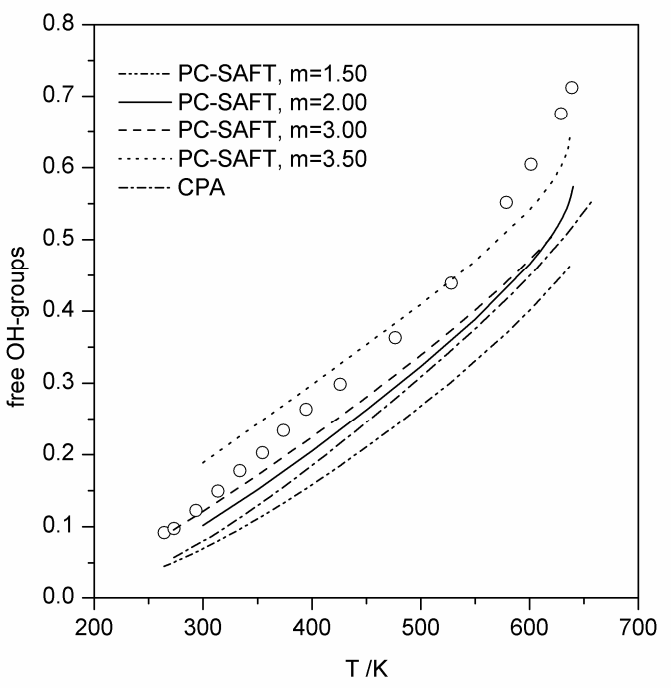

Figure 3. Free-OH groups $\left(\mathrm{X}^{\mathrm{A}}\right)$ of water vs. temperature. The lines represent calculations with PC-SAFT and CPA with different parameter sets. CPA parameters are from [14]. and PC-SAFT $(\mathrm{m}=2-3.5)$ results are taken from [11]. PC-SAFT Deleted: 12 with $m=1.5$ are taken from [6]. All parameters use the $4 \mathrm{C}$ scheme. Experimental Deleted: 13 data are taken from Luck [15]. 


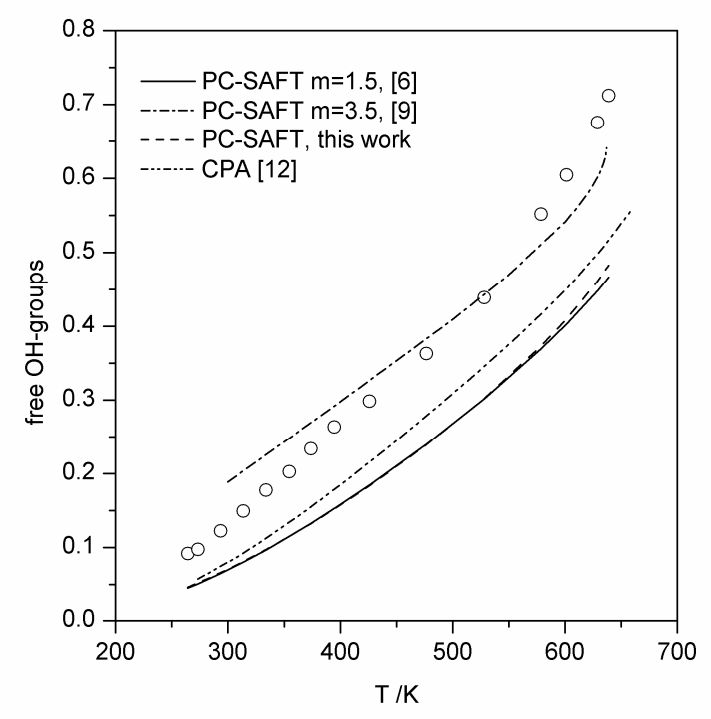

Figure 4. Free-OH groups $\left(\mathrm{X}^{\mathrm{A}}\right)$ of water vs. temperature using CPA and PC-SAFT with the 4C association scheme. PC-SAFT parameters are from [6] and [11] and CPA parameters are from [14]. PC-SAFT water parameters of this work are obtained from simultaneous fitting of vapour pressures, liquid density and enthalpy of vaporization data (segment diameter- $\sigma=2.0772 \AA$, dispersion energy- $\varepsilon / \mathrm{k}=140.39$ $\mathrm{K}$, segment number-m=2.61008, association energy- $\varepsilon^{\mathrm{HB}} / \mathrm{k}=1694.77 \mathrm{~K}$, association volume- $\left.\kappa^{\mathrm{HB}}=0.5879\right)$. The results with PC-SAFT of Grenner et al. 2006 [6] and with the parameter set estimated here are almost identical. Experimental data are taken from Luck [15]. 


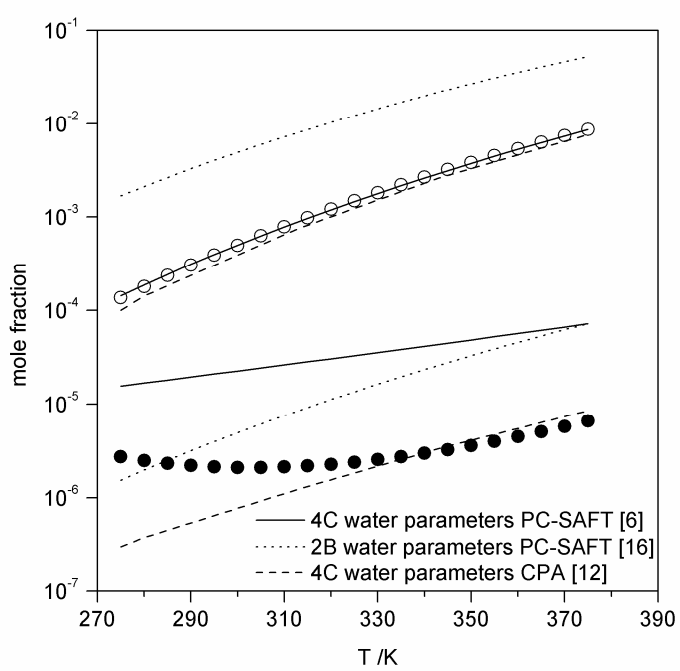

Figure 5. Water-hexane LLE with PC-SAFT $\left(\mathrm{k}_{\mathrm{ij}}=0\right)$ using two published sets of water parameters from [6] (4C scheme), [20] (2B scheme) and CPA $\left(\mathrm{k}_{\mathrm{ij}}=0\right)$ with parameters form [14] (4C scheme). The experimental data are taken from Deleted: 16 Tsonopoulos [21].

Deleted: 12

Deleted: 17 


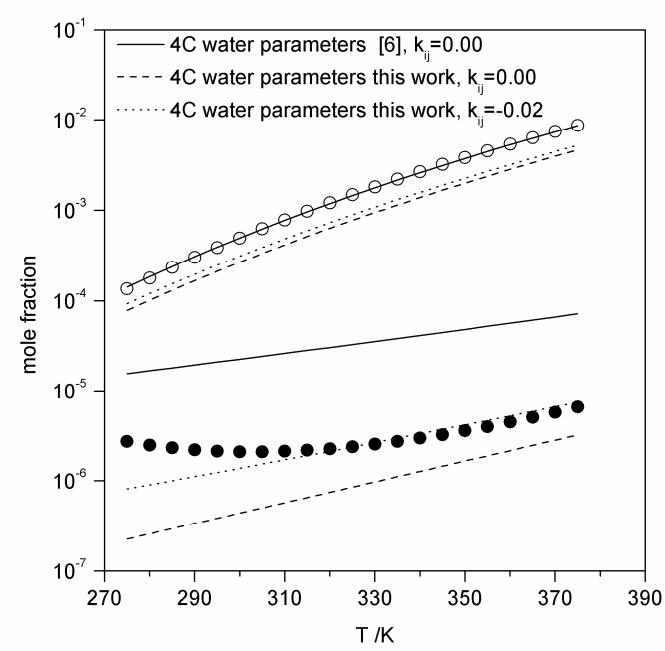

Figure 6. LLE water + hexane with PC-SAFT using the water 4C scheme and various parameter sets for water, from [6] and the ones presented here (caption of Figure 4). The experimental data are taken from Tsonopoulos [21].

Deleted: 17 